\title{
Mechanical Behavior of Electrodeposited Bulk Nanocrystalline Fe-Ni Alloys
}

\author{
Isao Matsui ${ }^{a, b}$, Hiroki Mori ${ }^{a}$, Tomo Kawakatsu ${ }^{a}$, Yorinobu Takigawa ${ }^{a}$, Tokuteru Uesugi ${ }^{a}$, \\ Kenji Higashi \\ ${ }^{a}$ Department of Materials Science, Osaka Prefecture University,1-1, Gakuen-cho, Sakai, Osaka, \\ 599-8531, Japan \\ ${ }^{b}$ Structural Materials Research Institute, National Institute of Advanced Industrial Science and \\ Technology - AIST, 2266-98, Shimo-Shidami, Moriyama-ku, Nagoya, 463-8560, Japan
}

Received: September 13, 2014; Revised: September 16, 2015

\begin{abstract}
Bulk nanocrystalline Fe-Ni alloys with Ni content of 40-55 at.\%, grain size of 12-15 nm, and hardness of 3.9-4.6 were prepared by an electrodeposition. The decrease in the hardness values as grain size decreased was discussed in terms of grain refinement effect, solid solution strengthening, and grain boundary relaxation strengthening. It was found that the change of $\mathrm{Ni}$ content could not significant solid solution strengthening, and there were no difference in the state of grain boundary for each sample. Micro X-ray diffraction analysis on the sample after tensile tests showed that the (200) texture was developed but full width at half maximum was not changed. This indicated the potency that the grain boundary activity would be induced by a tensile loading. The softening behavior of electrodeposited $\mathrm{Fe}-\mathrm{Ni}$ alloys would be related to the transition of the dominant deformation mechanisms.
\end{abstract}

Keywords: nanocrystalline metals, electrodeposition, Fe-Ni alloys, mechanical properties, micro $X$-ray diffraction

\section{Introduction}

Nanocrystalline metals with grain sizes less than $100 \mathrm{~nm}$ exhibit very high mechanical strength compared with materials having conventional grain size ${ }^{1}$. The strength of nanocrystalline metals strongly depends on the grain size, and extensive studies have demonstrated the grain size (Hall-Petch) effect in the nanometer range. In addition, alloying elements affect the strength of nanocrystalline materials $\mathrm{s}^{2,3}$. The strengthening behavior of a solid solution, due to not only intentional alloying elements but also light elements that are usually inadvertently incorporated within the materials during production, has been discussed. For example, Matsui et al. ${ }^{4}$ tracked the effect of substitutional sulfur and interstitial carbon contents in electrodeposited nanocrystalline $\mathrm{Ni}$ and found that solid-solution strengthening by carbon plays an important role in increasing the mechanical strength of the electrodeposited Ni. Recently, it was demonstrated that the state of the grain boundary, in addition to the grain size and solid-solution strengthening, also affects the strength of nanocrystalline metals. Nanocrystalline metals in an as-prepared state often contain nonequilibrium grain boundaries with excess dislocation, regions of misfit, or excess free volume ${ }^{5-7}$. Jang \& Atzmon ${ }^{6}$ conducted high-resolution transmission electron microscopy (TEM) and found that grain boundaries evolve gradually from an initial discontinuous structure into structures that are more in equilibrium during low-temperature annealing, which involves no measurable change in grain size or texture. Rupert et al. ${ }^{8}$ found that low-temperature treatments of electrodeposited nanocrystalline $\mathrm{Ni}-\mathrm{W}$ alloys can increase the hardness without any grain growth, which is

*e-mail: i-matsui@aist.go.jp termed grain-boundary-relaxation strengthening. Relaxation of the grain boundary has an appreciable effect on the strength; an increase in hardness of up to $\sim 20 \%$ was observed for electrodeposited nanocrystalline Fe-Ni alloys ${ }^{9}$. Further investigations, including those on grain-boundary-relaxation strengthening, are important to gain a deeper understanding of the strength of nanocrystalline metals.

In our previous study ${ }^{10}$, bulk nanocrystalline $\mathrm{Fe}-\mathrm{Ni}$ alloys with Ni content of 42-55 at.\% were electrodeposited and the tensile properties measured. The results showed that the tensile strength decreased from 1.87 to $1.61 \mathrm{GPa}$ with a decrease in the Ni content and grain size. The details of this behavior were not revealed or discussed. Therefore, the aim of the present study is to develop a better understanding of the mechanical properties for bulk nanocrystalline Fe-Ni alloys. We electrodeposited bulk nanocrystalline $\mathrm{Fe}-\mathrm{Ni}$ alloys with $\mathrm{Ni}$ content of 40-55 at.\% and grain size of 12-15 nm, and discuss the softening behavior in terms of the grain refinement effect, solid-solution strengthening, and grain-boundary-relaxation strengthening. This discussion points to the potential that the softening behavior is related to the transition of dominant deformation mechanisms from dislocation activity to grain boundary activity. Micro X-ray diffraction ( $\mu$ XRD) analysis of the samples after tensile tests was conducted to verify the possibility.

\section{Experimental Procedure}

Fe-Ni alloys were prepared employing the electrodeposition technique described in our previous study ${ }^{10}$. The bath composition in the present study is given in Table 1. Bulk 
Table 1. Bath composition for Fe-Ni alloys.

\begin{tabular}{ccc}
\hline Chemicals & Amount $(\mathbf{g} / \mathbf{L})$ & Purpose \\
\hline Iron sulfate & $70.0-135.0$ & Fe source \\
Nickel sulfamate & $140.0-215.0$ & Ni source \\
Nickel chloride & 20.0 & Passivation inhibitor \\
Boric acid & 40.0 & Complexing agent \\
Saccharin sodium & 5.0 & Stress reliever \\
Sodium lauryl sulfate & 0.3 & Pit prevention agent \\
\hline
\end{tabular}

samples with thickness of $\sim 0.7 \mathrm{~mm}$ were electrodeposited onto $\mathrm{Cu}$ substrates of commercial purity using two counter electrodes of titanium baskets with nickel iron plates $(99.8 \%)$ and nickel plates (99.98\%), varying the Ni content in the range of $40-55$ at. $\%$ by adjusting the $\mathrm{Ni} / \mathrm{Fe}$ ratio in the deposition bath. We assigned samples with labels that correspond to different $\mathrm{Ni}$ contents and electrodeposition conditions. All electrodeposition processes were performed for $\sim 192 \mathrm{~h}$ with a current density of $10 \mathrm{~mA} / \mathrm{cm}^{2}$, bath temperature of $50.0 \pm 0.5^{\circ} \mathrm{C}$, and $\mathrm{pH}$ of $2.2 \pm 0.1$. The bath temperature was strictly maintained by a heater using a proportional-integral-derivative controller. The $\mathrm{pH}$ of the solutions was maintained by the addition of drops of either $1.0 \mathrm{~mol} / \mathrm{L}$ sulfamic acid or $5.0 \mathrm{~mol} / \mathrm{L}$ sodium hydroxide.

The Ni content of the electrodeposits was determined by energy-dispersive $\mathrm{X}$-ray spectrometry analysis using a scanning electron microscope (Hitachi S-4800). TEM specimens with a diameter of $3 \mathrm{~mm}$ were prepared employing a twin-jet polishing technique and nitric acid-methanol solution $(20 \%$ by volume of $\mathrm{HNO}_{3}$ ) at $-30^{\circ} \mathrm{C}$ and $15 \mathrm{~V}$. The TEM specimens were examined using a JEOL JEM-2100F system operated at $200 \mathrm{kV}$. X-ray diffraction (XRD, Rigaku Ultimate IV) analysis and $\mu \mathrm{XRD}$ analysis (Rigaku SmartLab) were performed using $\mathrm{Cu} \mathrm{K} \alpha$ radiation to confirm structures and to estimate grain sizes. To evaluate the hardness of the electrodeposits, micro-Vickers hardness tests were conducted on bulk samples using a load of $500 \mathrm{~g}$ for $10 \mathrm{~s}$. Each reported data point represents the average value for at least 12 indentations. From the bulk samples, dog-bone specimens with a gauge length of $12 \mathrm{~mm}$, width of $4 \mathrm{~mm}$, and thickness of $0.7 \mathrm{~mm}$ were machined by electrical discharge machining for tensile tests. It is noted that the copper substrate was removed by mechanical polishing. Tensile tests were performed at a strain of $1 \times 10^{-3} \mathrm{~s}^{-1}$ and at room temperature. The plastic elongation of the specimen after fracture was measured by the change in the gauge length.

\section{Results and Discussion}

In total, six bulk samples were electrodeposited by varying the $\mathrm{Ni} / \mathrm{Fe}$ ratio in the deposition bath $(1.07,1.31$, $1.54,1.66,1.78$, and 2.98). This expanded upon our previous results for $\mathrm{Fe}-\mathrm{Ni}$ alloys that were limited to a $\mathrm{Ni} / \mathrm{Fe}$ ratio of 1.54-2.98 in the deposition bath ${ }^{10}$. All electrodeposition had good current efficiency of approximately $77 \%$. Figure 1 shows the effect of the $\mathrm{Ni} / \mathrm{Fe}$ ratio in the deposition bath on the Ni content of electrodeposited $\mathrm{Fe}-\mathrm{Ni}$ alloys. The $\mathrm{Ni}$ content of electrodeposits increased from 40 to 55 at.\% as the $\mathrm{Ni} / \mathrm{Fe}$ ratio increased from 1.07 to 2.98 .

Figure 2 presents the XRD patterns for the electrodeposited bulk samples with a Ni content of 40-55 at.\%, with each pattern showing a single-phase face-centered cubic (fcc)

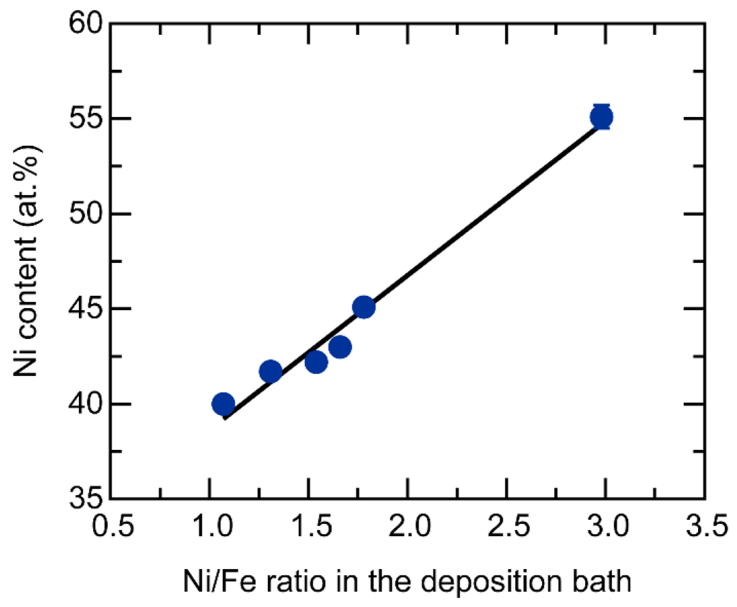

Figure 1. Effect of the Ni/Fe ratio of the deposition bath on the $\mathrm{Ni}$ content of electrodeposited Fe-Ni alloys.

structure. This result is inconsistent with results presented by McCrea et al. ${ }^{11}$, which showed a mixed body-centered cubic (bcc)/fcc structure in electrodeposited Fe-Ni alloys for $\mathrm{Ni}$ content ranging by approximately $\pm 10 \mathrm{wt} . \%$ around 40 wt.\% Ni. Meanwhile, Hong \& Fultz ${ }^{12}$ compared the phase boundaries of the bcc and fcc phases of Fe-Ni alloys obtained from nonequilibrium processing, such as thermal evaporation, sputtering, and ball milling. This comparison indicated that the phase boundaries depend on the fabrication processes and conditions. In fact, the single-phase fcc structure in electrodeposited $\mathrm{Fe}-\mathrm{Ni}$ alloys cannot be obtained when electrodeposition is conducted at current density of $30 \mathrm{~mA} / \mathrm{cm}^{2}$ or without sodium saccharin.

The grain sizes of the samples were estimated from the width of the (111) diffraction peak using Scherrer's equation and the results are presented in Figure 2. The calculated grain sizes ranged from 12 to $15 \mathrm{~nm}$. These grain sizes decreased with a decrease in the Ni content of electrodeposited alloys. Figure 3 shows a bright-field TEM image for electrodeposited bulk nanocrystalline Fe-55 at.\% Ni alloy. The alloy exhibits microstructures with a grain size of $\sim 15 \mathrm{~nm}$, which is comparable to the size calculated from the XRD peak width. No defined precipitate was observed in the TEM microstructure.

The mechanical behavior of the electrodeposited bulk nanocrystalline $\mathrm{Fe}-\mathrm{Ni}$ alloys was investigated by performing micro-Vickers hardness tests. Figure 4 shows the results of hardness tests plotted against the inverse square root of the grain size. Homogeneous hardness was observed for all samples. The standard deviation of the hardness values was $0.07 \mathrm{GPa}$. The hardness values decreased from 4.6 to $3.9 \mathrm{GPa}$ as the grain sizes decreased from 15 to $12 \mathrm{~nm}$ and/or Ni content decreased from 55 to 40 at.\%.

The results of hardness tests showed that the strength reduced with a decrease in grain size or Ni content. There are three factors that conceivably affect the mechanical strength of electrodeposited nanocrystalline metals: (i) the grain refinement effect; (ii) solid-solution strengthening; and (iii) grain-boundary-relaxation strengthening.

In the grain refinement effect, dislocation activity is greatly inhibited as the grain size reduces, whereas an increase in the grain boundary area enhances grain boundary activity. In the case of fcc metals, there is a transition in the dominant 


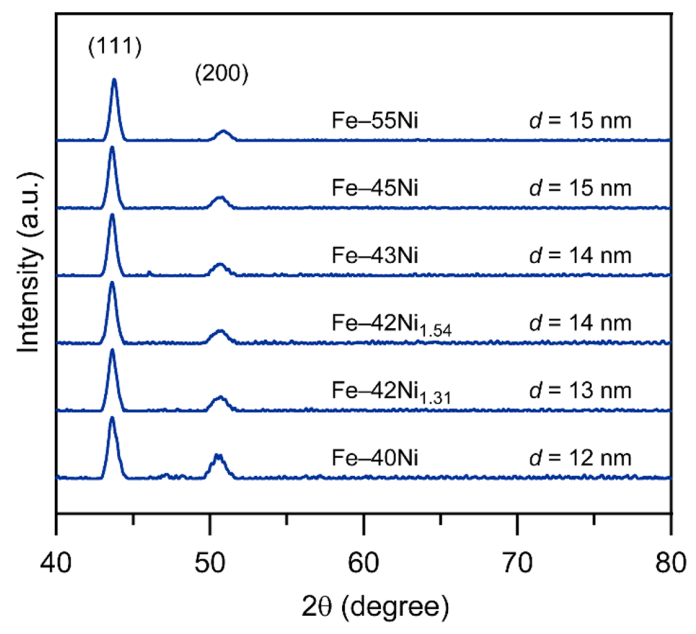

Figure 2. XRD patterns of electrodeposited bulk nanocrystalline Fe-Ni alloys. $d$ stands for the grain size calculated from the XRD determination of the (111) peak width.

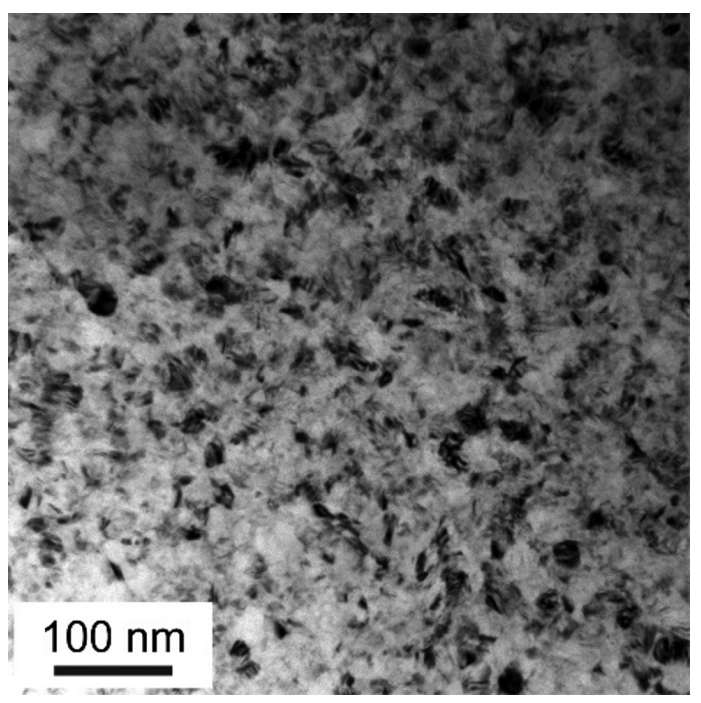

Figure 3. Bright-field TEM images of electrodeposited bulk nanocrystalline $\mathrm{Fe}-55 \mathrm{Ni}$ alloys.

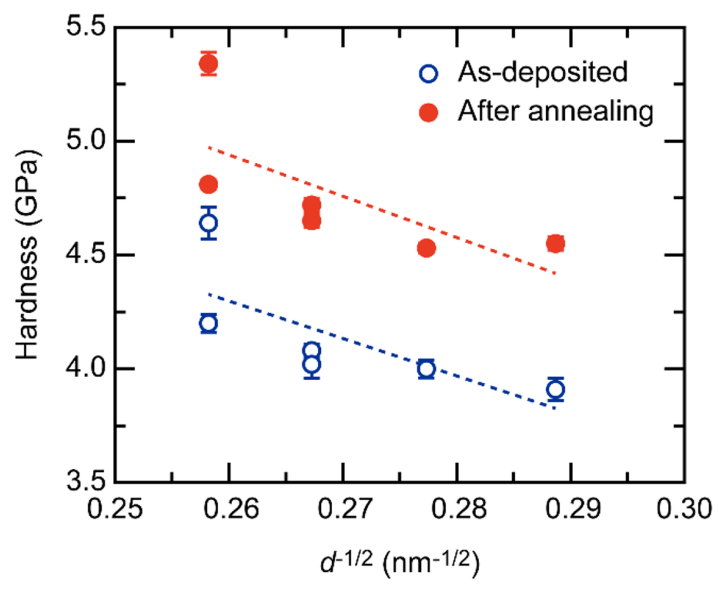

Figure 4. Hall-Petch plot of hardness for electrodeposited bulk nanocrystalline $\mathrm{Fe}-\mathrm{Ni}$ alloys in an as-deposited state and after annealing at $200{ }^{\circ} \mathrm{C}$ for $3 \mathrm{~h}$. deformation mechanism at grain sizes of $\sim 10-20 \mathrm{~nm}^{13-16}$. It is noted that the transition across the critical grain size is not sharp and occurs gradually owing to the relatively wide grain size distribution in nanocrystalline materials ${ }^{17}$. Experimentally, this transition usually corresponds to a maximum hardness and yield strength on a Hall-Petch plot, and reducing or constant strength despite the decrease in grain size (inverse Hall-Petch behavior) is observed in the grain size range of $\sim 3-20 \mathrm{~nm}^{18}$. Thus, the grain sizes of bulk nanocrystalline Fe-Ni alloys in this study are sufficiently low to facilitate the transition of the dominate deformation mechanism.

In the solid-solution strengthening of $\mathrm{Ni}$, the presence of a solute atom, different in size from an atom in the matrix, generates a localized misfit strain. The addition of Fe to $\mathrm{Ni}$ does not produce a large misfit strain; first-principle studies have reported that the calculated misfit strain due to $\mathrm{Fe}$ is only $-0.1 \%$ to $-0.2 \%{ }^{4,19}$, and studies employing the extended $\mathrm{X}$-ray absorption fine structure technique have reported low misfit strain of $0.2 \%{ }^{20}$. In our previous studies ${ }^{4,21}$, we discussed the use of misfit strains to estimate increases in yield stress and hardness arising from solid-solution strengthening. The strengthening increment due to the substitutional solute atom is given by

$$
\Delta \sigma=A \cdot|\varepsilon|^{4 / 3} \cdot c^{2 / 3}
$$

where $\sigma$ is the yield stress, $A$ is a fitting parameter, $\varepsilon$ is the misfit strain, and $c$ is the solute content. A modified Tabor relation, $H=3 \sigma$, was presented in the literature ${ }^{22,23}$ for nanocrystalline $\mathrm{Ni}$ (where $H$ is hardness). The increase in hardness due to the addition of solid solution $\Delta H$ is expressed as

$$
\Delta H=3.0 \cdot A \cdot|\varepsilon|^{4 / 3} \cdot c^{2 / 3}
$$

Equation 2 can be used to estimate the contribution of solidsolution strengthening to the hardness, taking $A=576 \mathrm{GPa}^{4}$ and $\varepsilon=-0.19 \%{ }^{4}$.

Iron contents of 5.0, 10.0, and 15.0 at.\% increase the hardness by approximately $0.06,0.19$, and $0.13 \mathrm{GPa}$, respectively. Even if the presence of nickel results in the solid-solution strengthening of Fe-Ni alloys, its contribution is subtle. Thus, the decrease in hardness is not due to a decrease in the Ni content of bulk nanocrystalline Fe-Ni alloys.

The final consideration is of grain-boundary-relaxation strengthening. In our previous study ${ }^{9}$, the addition of carboxylic acid to the deposition bath resulted in structures that were more in equilibrium and increased the hardness and tensile strength of the electrodeposited bulk nanocrystalline $\mathrm{Fe}-\mathrm{Ni}$ alloys even in the as-deposited state. This result suggested the possibility that a difference in bath composition produces different states of the grain boundaries. Bulk nanocrystalline Fe-Ni with $40-55$ at. $\% \mathrm{Ni}$ content was annealed at $200{ }^{\circ} \mathrm{C}$ for a total of $3 \mathrm{~h}$ to investigate the effect of the $\mathrm{Ni} / \mathrm{Fe}$ ratio in the deposition bath on the grain boundary relaxation behavior. Grain boundary relaxation occurs at or below approximately $400{ }^{\circ} \mathrm{C}$ for Fe-based alloys $s^{9,24,25}$. Hardness values after annealing are plotted against the inverse square root of grain size in Figure 4. An increase in the hardness of $13 \%-16 \%$ was observed, and this increase was not related to the $\mathrm{Ni} / \mathrm{Fe}$ ratio in the deposition bath. This indicates that the $\mathrm{Ni} / \mathrm{Fe}$ ratio has no effect on the grain-boundary-relaxation strengthening behavior of electrodeposits. Furthermore, 
the bulk nanocrystalline Fe-Ni alloys after grain boundary relaxation exhibited a decrease in hardness from 5.3 to $4.5 \mathrm{GPa}$ with a decrease in grain size from 15 to $12 \mathrm{~nm}$ (i.e., inverse Hall-Petch behavior).

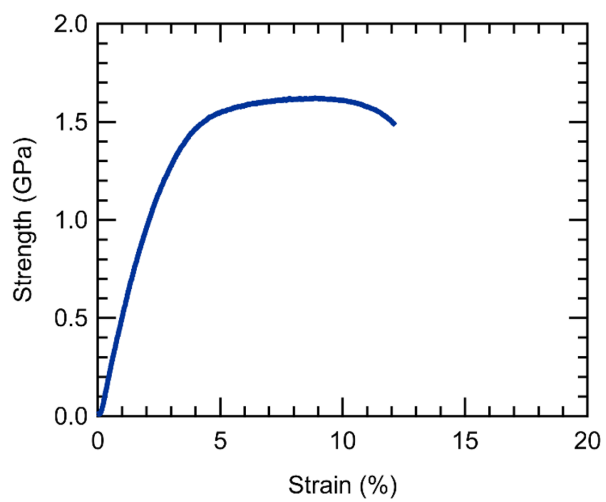

Figure 5. Tensile behavior of electrodeposited bulk nanocrystalline Fe-Ni alloys with Ni content of 44 at.\%.

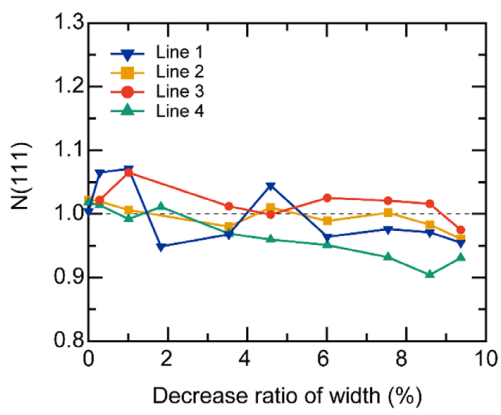

(a)

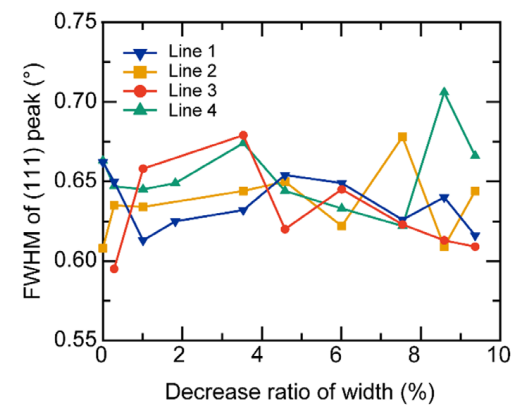

(c)
The above results and discussion indicate that the decrease in the hardness values of electrodeposited bulk nanocrystalline $\mathrm{Fe}-\mathrm{Ni}$ alloys in this study as the grain size decreased from 15 to $12 \mathrm{~nm}$ was due to refinement of the grain size. As described earlier, the deformation mechanism changes from dislocation activity to grain boundary activity at a critical grain size. The grain size of electrodeposited Fe-Ni alloys in this study would be smaller than the crossover value because the alloys showed inverse Hall-Petch behavior. It is likely that the dominant deformation mechanism of electrodeposited Fe$\mathrm{Ni}$ alloys is grain boundary activity. For further investigation of the deformation mechanism, bulk nanocrystalline Fe-Ni was prepared by electrodeposition with a $\mathrm{Ni} / \mathrm{Fe}$ ratio of 1.54 , and a tensile test was conducted and $\mu$ XRD techniques were then employed to monitor the structural evolutions.

Figure 5 shows the stress-strain curves of bulk nanocrystalline Fe-Ni alloys with Ni content of 43 at.\% and grain size of $14 \mathrm{~nm}$. The alloys exhibited tensile strength of $1.62 \mathrm{GPa}$ and high plastic deformation of $11.7 \%$. We examined structural evolutions on $\mathrm{Fe}-\mathrm{Ni}$ alloys after fracture using $\mu \mathrm{XRD}$ techniques. Figure $6 \mathrm{a}, \mathrm{b}$ shows the diffraction intensity of

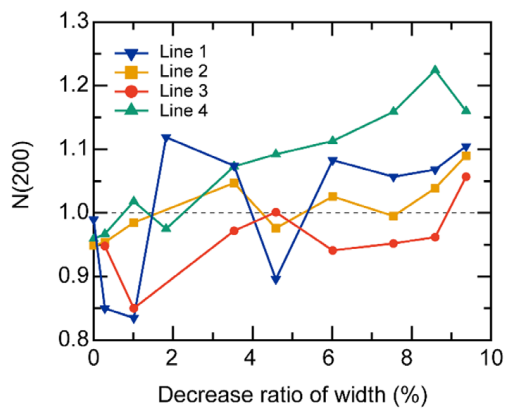

(b)

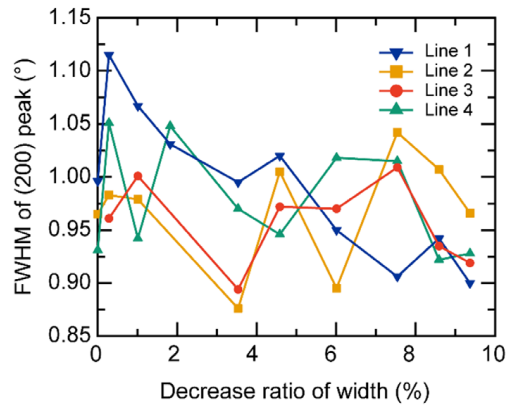

(d)

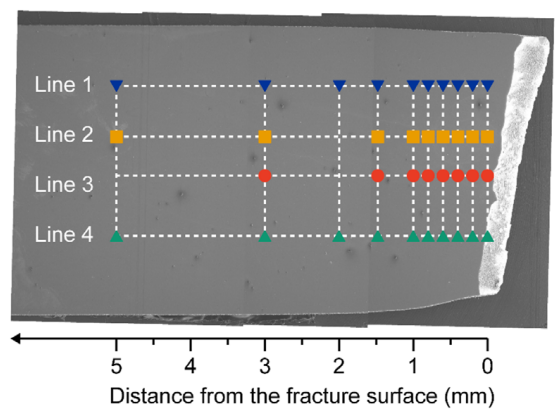

(e)

Figure 6. Normalized diffraction intensity of the (a) (111) peak and (b) (200) peak for the electrodeposited bulk nanocrystalline Fe-43Ni alloys after fracture. FWHM of the (c) (111) peak and (d) (200) peak for the electrodeposited bulk nanocrystalline Fe-43Ni alloys after fracture. (e) Scanning electron microscopy image showing the gauge section of the electrodeposited bulk nanocrystalline Fe-43Ni alloys. 
(111) and (200) peaks for bulk nanocrystalline Fe-Ni alloys as a function of the ratio of the decrease in width. Note that the diffraction intensities were normalized by the respective values of a randomly oriented $\gamma$-iron powder standard from the International Center for Diffraction database:

$$
N(h k l)=\frac{I_{h k l}}{I_{111}+I_{200}} / \frac{I_{h k l}^{0}}{I_{111}^{0}+I_{200}^{0}}
$$

where $N(h k l)$ is the normalized diffraction intensity of $h k l$ reflections, $I_{\mathrm{hkl}}$ is the diffraction intensity of $h k l$ reflections for the electrodeposited bulk nanocrystalline Fe-Ni alloys, and $I_{h k l}^{0}$ is the diffraction intensity of $h k l$ reflections for randomly oriented $\gamma$-iron powder.

Figure $6 \mathrm{c}, \mathrm{d}$ shows the full width at half maximum (FWHM) of (111) and (200) peaks for bulk nanocrystalline $\mathrm{Fe}-\mathrm{Ni}$ alloys as a function of the ratio of the decrease in width. Figure 6e presents a scanning electron microscopy image showing the actual tensile test specimen of sample $\mathrm{Fe}-43 \mathrm{Ni}$ after fracture along with the measurement points of $\mu$ XRD analysis.

Figure $6 \mathrm{a}, \mathrm{b}$ shows that the normalized intensity of the (111) peak decreased while that of the (200) peak increased for bulk nanocrystalline $\mathrm{Fe}-\mathrm{Ni}$ alloys with an increase in the ratio of the decrease in width. Meanwhile, (111) and (200) texture components were developed for the coarse-grained $\mathrm{Ni}^{26,27}$. In the both nanocrystalline and coarse-grained metals, plastic deformation introduces a texture.

Figure $6 \mathrm{c}$, d shows that the FWHM values of (111) and (200) peaks did not change obviously with an increase in the ratio of the decrease in width. In contrast, the plastic deformation of coarse-grained polycrystalline metals often leads to peak broadening and a decrease in FWHM, which is attributed to a reduction in grain size and/or an increase in dislocation density ${ }^{26}$. Thus, the observed no change in FWHM for the present bulk nanocrystalline $\mathrm{Fe}-\mathrm{Ni}$ alloys could be due to any change in the grain size and/or dislocation density. This indicates that the grain boundary activity is induced by tensile loading of electrodeposited bulk nanocrystalline Fe-Ni alloys.

Recent studies ${ }^{17,28-30}$ have indicated that plastic deformation causes grain growth in some nanocrystalline

\section{References}

1. Meyers MA, Mishra A and Benson DJ. Mechanical properties of nanocrystalline materials. Progress in Materials Science. 2006; 51(4):427-556. http://dx.doi.org/10.1016/j.pmatsci.2005.08.003.

2. Rupert TJ, Trenkle JC and Schuh CA. Enhanced solid solution effects on the strength of nanocrystalline alloys. Acta Materialia. 2011; 59(4):1619-1631. http://dx.doi.org/10.1016/j. actamat.2010.11.026.

3. Guduru RK, Scattergood RO, Koch CC, Murty KL, Guruswamy $\mathrm{S}$ and McCarter MK. Mechanical properties of nanocrystalline $\mathrm{Fe}-\mathrm{Pb}$ and Fe-A12O3. Scripta Materialia. 2006; 54(11):18791883. http://dx.doi.org/10.1016/j.scriptamat.2006.02.014.

4. Matsui I, Uesugi T, Takigawa Y and Higashi K. Effect of interstitial carbon on the mechanical properties of electrodeposited bulk nanocrystalline Ni. Acta Materialia. 2013; 61(9):3360-3369. http://dx.doi.org/10.1016/j.actamat.2013.02.025. metals and alloys, in contrast to the grain size reduction for coarse-grained materials. This stress-induced grain growth in nanocrystalline metals and alloys has been attributed to grain boundary migration or grain rotation ${ }^{17}$. Several studies also showed the developments of (111) and (200) textures ${ }^{17,26}$. However, for electrodeposited bulk nanocrystalline $\mathrm{Fe}-\mathrm{Ni}$ alloys in this study, there was no obvious grain growth or development for either (111) or (200) texture. This difference suggests that the large plastic elongation of over $10 \%$ was introduced by a slight difference in grain boundary activity compared with the case for nanocrystalline metals with plastic elongation of $\sim 5 \%$. Although the origin of the deformation mechanisms in the electrodeposited bulk nanocrystalline $\mathrm{Fe}-\mathrm{Ni}$ alloys is not clear at present, the results of this study point to the dominant deformation mechanism being grain boundary activity.

\section{Conclusions}

We electrodeposited bulk nanocrystalline Fe-Ni alloys, varying the $\mathrm{Ni} / \mathrm{Fe}$ ratio in the deposition bath, to develop a better understanding of the mechanical behavior. The bulk nanocrystalline $\mathrm{Fe}-\mathrm{Ni}$ alloys with $\mathrm{Ni}$ content of 40-55 at.\% exhibited inverse Hall-Petch behavior in hardness tests. The results of low-thermal treatments on the electrodeposited alloys indicate that varying the $\mathrm{Ni} / \mathrm{Fe}$ ratio in the deposition bath had no effect on the state of grain boundaries. The results also revealed that decreases in the hardness values were mainly due to the grain refinement effect. In addition, $\mu$ XRD analysis of the bulk nanocrystalline $\mathrm{Fe}-\mathrm{Ni}$ alloys after fracture showed no change in the FWHM values of (111) and (200) peaks. This indicates that there was no change in grain size and/or dislocation density. The results and discussion of this study point to the dominant deformation mechanism of electrodeposited bulk nanocrystalline $\mathrm{Fe}-\mathrm{Ni}$ alloys being grain boundary activity.

\section{Acknowledgements}

This study was supported by a Grant-in-Aid for Scientific Research (C) (25390031) and a Grant-in-Aid for JSPS Fellows from The Ministry of Education, Culture, Sports, Science and Technology (MEXT), Japan.

5. Wu XL and Zhu YT. Partial-dislocation-mediated processes in nanocrystalline $\mathrm{Ni}$ with nonequilibarium grain boundaries. Applied Physics Letters. 2006; 89(3):031922. http://dx.doi. org/10.1063/1.2227639.

6. Jang D and Atzmon M. Grain-boundary relaxation and its effect on plasticity in nanocrystalline Fe. Journal of Applied Physics. 2006; 99(8):083504. http://dx.doi.org/10.1063/1.2187417.

7. Ranganathan S, Divakar R and Raghunathan VS. Interface structures in nanocrystalline materials. Scripta Materialia. 2001; 44(8-9):1169-1174. http://dx.doi.org/10.1016/S13596462(01)00678-9.

8. Rupert TJ, Trelewicz JR and Schuh CA. Grain boundary relaxation strengthening of nanocrystalline Ni-W alloys. Journal of Materials Research. 2012; 27(9):1285-1294. http://dx.doi. org/10.1557/jmr.2012.55. 
9. Matsui I, Mori H, Kawakatsu T, Takigawa Y, Uesugi T and Higashi K. Enhancement in mechanical properties of bulk nanocrystalline $\mathrm{Fe}-\mathrm{Ni}$ alloys electrodeposited using propionic acid. Materials Science and Engineering A. 2014; 607:505-510. http://dx.doi.org/10.1016/j.msea.2014.04.042.

10. Matsui I, Kawakatsu T, Takigawa Y, Uesugi T and Higashi K. Fabrication of bulk nanocrystalline Fe-Ni alloys with high strength and high ductility by an electrodeposition. Materials Letters. 2014; 116:71-74. http://dx.doi.org/10.1016/j.matlet.2013.10.108.

11. McCrea JL, Palumbo G, Hibbard GD and Erb U. Properties and applications for electrodeposited nanocrystalline $\mathrm{Fe}-\mathrm{Ni}$ alloys. Rev Adv Mater Sci. 2003; 5:252-258.

12. Hong LB and Fultz B. Two-phase coexistence in Fe-Ni alloys synthesized by ball milling. Journal of Applied Physics. 1996; 79(8):3946-3955. http://dx.doi.org/10.1063/1.361821.

13. Ebrahimi F, Bourne GR, Kelly MS and Matthews TE. Mechanical properties of nanocrystalline nickel produced by electrodeposition. Nanostructured Materials. 1999; 11(3):343-350. http://dx.doi. org/10.1016/S0965-9773(99)00050-1.

14. Schuh CA, Nieh TG and Iwasaki H. The effect of solid solution $\mathrm{W}$ additions on the mechanical properties of nanocrystalline $\mathrm{Ni}$. Acta Materialia. 2003; 51(2):431-443. http://dx.doi.org/10.1016/ S1359-6454(02)00427-5.

15. Yamakov V, Wolf D, Phillpot SR, Mukherjee AK and Gleiter H. Deformation-mechanism map for nanocrystalline metals by molecular-dynamics simulation. Nature Materials. 2004; 3(1):43-47. http://dx.doi.org/10.1038/nmat1035. PMid:14704784.

16. Cheung C, Djuanda F, Erb U and Palumbo G. Electrodeposition of nanocrystalline Ni-Fe alloys. Nanostructured Materials. 1995; 5(5):513-523. http://dx.doi.org/10.1016/0965-9773(95)00264-F.

17. Fan GJ, Fu LF, Choo H, Liaw PK and Browning ND. Uniaxial tensile plastic deformation and grain growth of bulk nanocrystalline alloys. Acta Materialia. 2006; 54(18):4781-4792. http://dx.doi. org/10.1016/j.actamat.2006.06.016.

18. Giga A, Kimoto Y, Takigawa Y and Higashi K. Demonstration of an inverse Hall-Petch relationship in electrodeposited nanocrystalline Ni-W alloys through tensile testing. Scripta Materialia. 2006; 55(2):143-146. http://dx.doi.org/10.1016/j. scriptamat.2006.03.047.

19. Kim D, Shang SL and Liu ZK. Effects of alloying elements on elastic properties of $\mathrm{Ni}$ by first-principles calculations. Computational Materials Science. 2009; 47(1):254-260. http:// dx.doi.org/10.1016/j.commatsci.2009.07.014.

20. Scheuer $U$ and Lengeler B. Lattice distortion of solute atoms in metals studied by X-ray-absorption fine structure. Physical Review B: Condensed Matter and Materials Physics. 1991; 44(18):9883-9894. http://dx.doi.org/10.1103/PhysRevB.44.9883. PMid:9998990.
21. Uesugi $T$ and Higashi K. First-principles studies on lattice constants and local lattice distortions in solid solution aluminum alloys. Computational Materials Science. 2013; 67:1-10. http:// dx.doi.org/10.1016/j.commatsci.2012.08.037.

22. Torre FD, Van Swygenhoven H and Victoria M. Nanocrystalline electrodeposited Ni: microstructure and tensile properties. Acta Materialia. 2002; 50(15):3957-3970. http://dx.doi.org/10.1016/ S1359-6454(02)00198-2.

23. Brooks I, Lin P, Palumbo G, Hibbard GD and Erb U. Analysis of hardness-tensile strength relationships for electroformed nanocrystalline materials. Materials Science and Engineering A. 2008; 491(1-2):412-419. http://dx.doi.org/10.1016/j. msea.2008.02.015.

24. Kotan H, Darling KA, Saber M, Scattergood RO and Koch CC. Thermal stability and mechanical properties of nanocrystalline Fe-Ni-Zr alloys prepared by mechanical alloying. Journal of Materials Science. 2013; 48(24):8402-8411. http://dx.doi. org/10.1007/s10853-013-7652-7.

25. Kotan H, Saber M, Koch CC and Scattergood RO. Effect of annealing on microstructure, grain growth, and hardness of nanocrystalline Fe-Ni alloys prepared by mechanical alloying. Materials Science and Engineering A. 2012; 552:310-315. http://dx.doi.org/10.1016/j.msea.2012.05.045.

26. Fan GJ, Li L, Yang B, Choo H, Liaw PK, Saleh TA, et al. In situ neutron-diffraction study of tensile deformation of a bulk nanocrystalline alloy. Materials Science and Engineering A. 2009; 506(1-2):187-190. http://dx.doi.org/10.1016/j.msea.2008.11.054.

27. Jia N, Peng RL, Wang YD, Chai GC, Johansson S, Wang $\mathrm{G}$, et al. Interactions between the phase stress and the grainorientation-dependent stress in duplex stainless steel during deformation. Acta Materialia. 2006; 54(15):3907-3916. http:// dx.doi.org/10.1016/j.actamat.2006.04.019.

28. Fan GJ, Fu LF, Wang YD, Ren Y, Choo H, Liaw PK, et al. Uniaxial tensile plastic deformation of a bulk nanocrystalline alloy studied by a high-energy x-ray diffraction technique. Applied Physics Letters. 2006; 89(10):101918. http://dx.doi. org/10.1063/1.2348783.

29. Fan GJ, Wang YD, Fu LF, Choo H, Liaw PK, Ren Y, et al. Orientation-dependent grain growth in a bulk nanocrystalline alloy during the uniaxial compressive deformation. Applied Physics Letters. 2006; 88(17):171914.

30. Gianola DS, Van Petegem S, Legros M, Brandstetter S, Van Swygenhoven H and Hemker KJ. Stress-assisted discontinuous grain growth and its effect on the deformation behavior of nanocrystalline aluminum thin films. Acta Materialia. 2006; 54(8):2253-2263. http://dx.doi.org/10.1016/j.actamat.2006.01.023. 